\title{
Ex vivo lung perfusion with adenosine A2A receptor agonist allows prolonged cold preservation of lungs donated after cardiac death
}

\author{
Cynthia E. Wagner, MD, ${ }^{\mathrm{a}}$ Nicolas H. Pope, MD, ${ }^{\mathrm{a}}$ Eric J. Charles, MD, ${ }^{\mathrm{a}}$ Mary E. Huerter, MD, ${ }^{\mathrm{a}}$ \\ Ashish K. Sharma, MBBS, PhD, ${ }^{a}$ Morgan D. Salmon, PhD, ${ }^{a}$ Benjamin T. Carter, BS, ${ }^{b}$ Mark H. Stoler, MD, \\ Christine L. Lau, MD, MBA, ${ }^{a}$ Victor E. Laubach, $\mathrm{PhD},{ }^{\mathrm{a}}$ and Irving L. Kron, $\mathrm{MD}^{\mathrm{a}}$
}

\begin{abstract}
Objective: Ex vivo lung perfusion has been successful in the assessment of marginal donor lungs, including donation after cardiac death (DCD) donor lungs. Ex vivo lung perfusion also represents a unique platform for targeted drug delivery. We sought to determine whether ischemia-reperfusion injury would be decreased after transplantation of DCD donor lungs subjected to prolonged cold preservation and treated with an adenosine $\mathrm{A} 2 \mathrm{~A}$ receptor agonist during ex vivo lung perfusion.
\end{abstract}

Methods: Porcine DCD donor lungs were preserved at $4^{\circ} \mathrm{C}$ for 12 hours and underwent ex vivo lung perfusion for 4 hours. Left lungs were then transplanted and reperfused for 4 hours. Three groups ( $n=4$ /group) were randomized according to treatment with the adenosine A2A receptor agonist ATL-1223 or the dimethyl sulfoxide vehicle: Infusion of dimethyl sulfoxide during ex vivo lung perfusion and reperfusion (DMSO), infusion of ATL-1223 during ex vivo lung perfusion and dimethyl sulfoxide during reperfusion (ATL-E), and infusion of ATL-1223 during ex vivo lung perfusion and reperfusion (ATL-E/R). Final $\mathrm{PaO}_{2} / \mathrm{FIO}_{2}$ ratios (arterial oxygen partial pressure/fraction of inspired oxygen) were determined from samples obtained from the left superior and inferior pulmonary veins.

Results: Final $\mathrm{PaO}_{2} / \mathrm{FIO}_{2}$ ratios in the ATL-E/R group (430.1 $\pm 26.4 \mathrm{~mm} \mathrm{Hg}$ ) were similar to final $\mathrm{PaO}_{2} / \mathrm{FIO}_{2}$ ratios in the ATL-E group $(413.6 \pm 18.8 \mathrm{~mm} \mathrm{Hg})$, but both treated groups had significantly higher final $\mathrm{PaO}_{2} / \mathrm{FIO}_{2}$ ratios compared with the dimethyl sulfoxide group $(84.8 \pm 17.7 \mathrm{~mm} \mathrm{Hg})$. Low oxygenation gradients during ex vivo lung perfusion did not preclude superior oxygenation capacity during reperfusion.

Conclusions: After prolonged cold preservation, treatment of DCD donor lungs with an adenosine $\mathrm{A} 2 \mathrm{~A}$ receptor agonist during ex vivo lung perfusion enabled $\mathrm{PaO}_{2} / \mathrm{FIO}_{2}$ ratios greater than $400 \mathrm{~mm} \mathrm{Hg}$ after transplantation in a preclinical porcine model. Pulmonary function during ex vivo lung perfusion was not predictive of outcomes after transplantation. ( $\mathrm{J}$ Thorac Cardiovasc Surg $2016 ; 151: 538-46)$

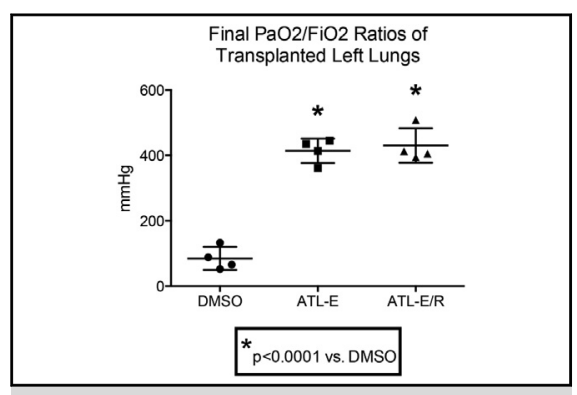

The treated groups (ATL-E and ATL-E/R) had higher final $\mathrm{PaO}_{2} / \mathrm{FlO}_{2}$ ratios than the DMSO group.

\section{Central Message}

The current shortage of donor lungs may be significantly reduced by treating marginal donor lungs with an A2AR agonist during EVLP.

\section{Perspective}

IRI after transplantation of DCD donor lungs subjected to prolonged cold preservation is attenuated by targeted treatment with an A2AR agonist delivered during EVLP in a preclinical porcine model. Poor lung function during EVLP does not predict outcomes after transplantation. Clinical translation may significantly increase the number of donor lungs available for transplantation.

See Editorial Commentary page 547.

See Editorial page 315.
From the ${ }^{\text {a Department }}$ of Surgery, Division of Thoracic and Cardiovascular Surgery, University of Virginia, Charlottesville, Va; ${ }^{b}$ School of Medicine, University of Virginia, Charlottesville, Va; and ${ }^{\mathrm{c}}$ Department of Pathology, University of Virginia, Charlottesville, Va

Funded by National Institutes of Health grants T32 HL007849 and R01 HL130053. Read at the 95th Annual Meeting of The American Association for Thoracic Surgery, Seattle, Washington, April 25-29, 2015.

Received for publication April 28, 2015; revisions received July 13, 2015; accepted for publication July 19, 2015; available ahead of print Aug 28, 2015.

Address for reprints: Irving L. Kron, MD, Department of Surgery, Division of Thoracic and Cardiovascular Surgery, University of Virginia, PO Box 800679, Charlottesville, VA 22908 (E-mail: ilk@virginia.edu).

0022-5223/\$36.00

Copyright $($ c 2016 by The American Association for Thoracic Surgery

http://dx.doi.org/10.1016/j.jtcvs.2015.07.075
The number of patients on the waiting list continues to exceed the number of patients who undergo lung transplantation each year, although recent advances in donor selection and lung preservation have the potential to close

Scanning this QR code will take you to the article title page. To view the AATS 2015 Webcast, see the URL at the end of the article. 


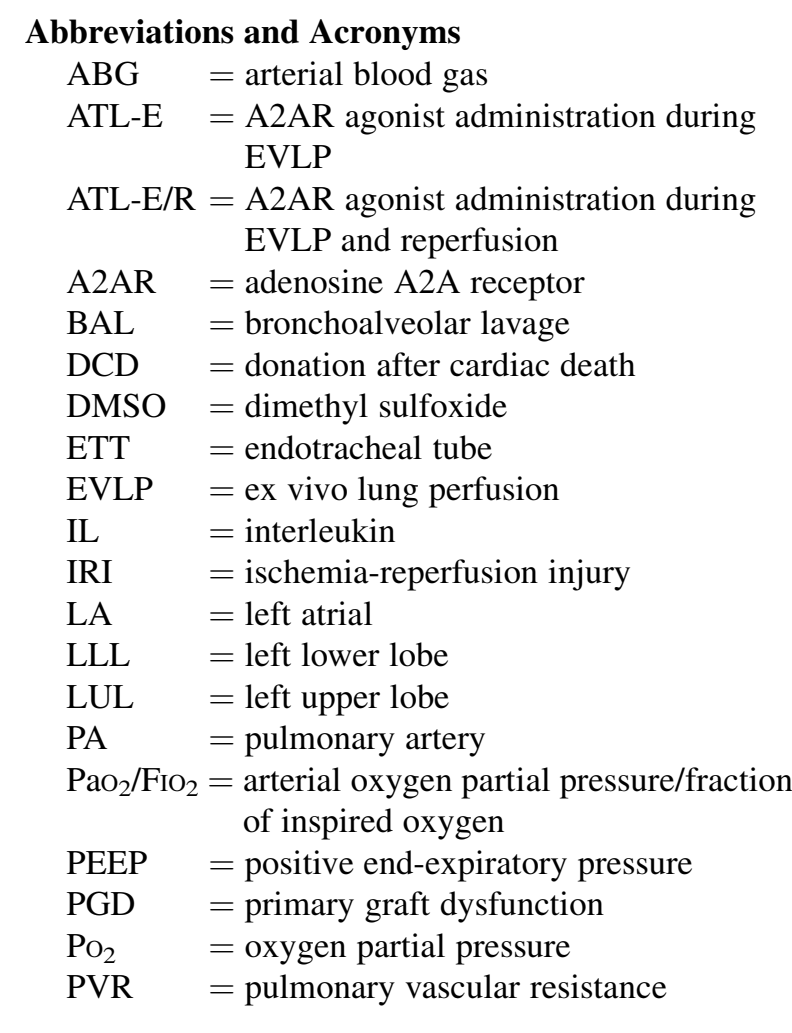

this gap. ${ }^{1}$ Lungs are usually selected from donors after brain death, yet only $15 \%$ to $20 \%$ of these lungs are deemed suitable and procured for transplantation after conservative evaluation. Marginal donor lungs, including those from donation after cardiac death (DCD) donors, represent an additional source for transplantation, but use of these lungs has been linked to increased mortality and primary graft dysfunction (PGD) in some studies. ${ }^{2,3}$ PGD is mediated by ischemia-reperfusion injury (IRI) and is associated with significant early and late mortality, ${ }^{4,5}$ as well as progression to bronchiolitis obliterans syndrome and delayed graft failure. ${ }^{6,7}$

Cold preservation of donor lungs reduces metabolic demand during ischemic storage but inhibits cellular regeneration that may be crucial before marginal donor lungs are transplanted. Normothermic ex vivo lung perfusion (EVLP) was initially developed to assess the function of lungs from DCD donors before transplantation. ${ }^{8}$ EVLP was subsequently modified to allow prolonged preservation of marginal donor lungs, ${ }^{9}$ and a pivotal clinical trial established noninferior outcomes after transplantation of marginal donor lungs passively rehabilitated with EVLP compared with conventional donor lungs. ${ }^{10}$ EVLP also offers a unique platform for targeted drug delivery to actively treat marginal donor lungs. We have previously demonstrated that the adenosine A2A receptor (A2AR) agonist ATL-1223 exerts anti-inflammatory effects and reduces IRI when administered to DCD donor lungs during EVLP in a porcine model of lung transplantation. ${ }^{11}$

The purpose of this study was to determine whether administration of ATL-1223 during EVLP would decrease IRI after transplantation of DCD donor lungs subjected to prolonged 12-hour cold preservation and whether further administration during reperfusion would augment this protection in a preclinical porcine model, with important implications to expand the donor lung pool by including DCD donors and allowing cross-country retrieval. We hypothesized that IRI would be reduced after transplantation of donor lungs treated with ATL-1223 during EVLP compared with lungs that received dimethyl sulfoxide (DMSO) vehicle, and that IRI would be further attenuated by continued administration of ATL-1223 to the recipient during reperfusion.

\section{MATERIALS AND METHODS \\ Animals}

This study was approved by the Institutional Animal Care and Use Committee at the University of Virginia. Animals received humane treatment in accordance with the "Guide for Care and Use of Laboratory Animals" from the National Institutes of Health.

\section{Study Design}

Mature domestic swine (19-35 kg) of both genders were randomized to 3 different groups $(\mathrm{n}=4$ /group) according to treatment with the A2AR agonist ATL-1223. Donor swine underwent hypoxic arrest followed by 15 minutes of warm ischemia. Lungs were procured and preserved at $4^{\circ} \mathrm{C}$ for 12 hours before undergoing normothermic EVLP for 4 hours. Left lungs were then transplanted into size-matched recipients and reperfused for 4 hours. The DMSO group received an infusion of DMSO (vehicle) during EVLP and reperfusion. The ATL-E group received an infusion of ATL-1223 during EVLP and an infusion of DMSO during reperfusion, and the ATL-E/R group received an infusion of ATL-1223 during EVLP and reperfusion.

\section{Donor Lung Procurement}

Donor animals were anesthetized, weighed, and prepped for a median sternotomy. After induction, animals were intubated and maintained under general anesthesia with isoflurane. Animals were ventilated with $100 \%$ oxygen before initial donor arterial blood gas (ABG) analysis. Heparin was not administered to donor animals. The endotracheal tube (ETT) was clamped, and donor animals underwent hypoxic arrest. Death was confirmed by cessation of electrocardiographic activity and absence of heart sounds. Animals were not touched for a 15-minute period of warm ischemia. Lungs were ventilated throughout the last 5 minutes of this time. A median sternotomy was performed. The main pulmonary artery (PA) was cannulated near the bifurcation with a cardioplegia cannula, and $500 \mu \mathrm{g}$ prostaglandin $\mathrm{E}_{1}$ (Pfizer Inc, New York, NY) was administered The main PA was clamped proximally, the left atrial (LA) appendage was vented, and the lungs were flushed with $1.5 \mathrm{~L}$ of $4^{\circ} \mathrm{C}$ Perfadex (XVIVO Perfusion, Englewood, Colo). Topical cold slush was applied. At the completion of the flush, the heart and lungs were removed en bloc. A funnel-shaped cannula with a pressure port (XVIVO Perfusion) was sewn to the LA cuff with a running 4-0 Prolene suture, a cannula with a pressure port (XVIVO Perfusion) was tied within the main PA, and a 7.0-mm ETT with the balloon removed was tied within the trachea. Lungs were inflated with gentle positive end-expiratory pressure (PEEP), and the ETT was clamped. A 500-mL retrograde flush with $4^{\circ} \mathrm{C}$ Perfadex 
was then performed. The lungs were submerged in $4^{\circ} \mathrm{C}$ Perfadex, surrounded by a double layer of cold slush, and stored at $4^{\circ} \mathrm{C}$ for 12 hours. Lungs were flushed antegrade with $500 \mathrm{~mL} 4^{\circ} \mathrm{C}$ Perfadex immediately before EVLP.

\section{Ex Vivo Lung Perfusion}

The EVLP circuit was primed with $2 \mathrm{~L}$ Steen solution (XVIVO Perfusion, Englewood, Colo) supplemented with 10,000 units heparin, $500 \mathrm{mg}$ methylprednisolone, and $500 \mathrm{mg}$ cefazolin. Perfusate was drained from the venous (LA) cannula into the venous reservoir and warmed to $37^{\circ} \mathrm{C}$, deoxygenated with a mixture of $86 \%$ nitrogen, $8 \%$ carbon dioxide, and $6 \%$ oxygen gas, and pumped into the arterial (PA) cannula (Medtronic BioMedicus centrifugal pump, Eden Prairie, Minn). Lungs were placed within the EVLP chamber (XVIVO Perfusion) and de-aired, and low flow $(0.15 \mathrm{~mL} / \mathrm{min})$ through the lungs was established to initiate EVLP. The height of the venous reservoir was adjusted to maintain LA pressures between 0 and $5 \mathrm{~mm} \mathrm{Hg}$. PA pressures were dependent on perfusate flow. Throughout the first 30 minutes of EVLP, flow was titrated up to $40 \%$ of estimated cardiac output $(100 \mathrm{~mL} / \mathrm{kg} / \mathrm{min})$, and perfusate was warmed to $37^{\circ} \mathrm{C}$. After 30 minutes of EVLP, lungs were ventilated on room air (tidal volume $10 \mathrm{~mL} / \mathrm{kg}$, respiratory rate 8 beats $/ \mathrm{min}$, PEEP $5 \mathrm{~cm} \mathrm{H}_{2} \mathrm{O}$ ). EVLP was performed for 4 hours. Oxygenation was assessed every hour by increasing the $\mathrm{FIO}_{2}$ to $100 \%$ for 15 minutes before oxygen partial pressure $\left(\mathrm{PO}_{2}\right)$ analysis. Samples taken from the venous and arterial arms of the circuit allowed calculation of the oxygenation gradient across the pulmonary vasculature. Other parameters recorded every hour included LA pressure, PA pressure, peak airway pressure, mean airway pressure, and plateau pressure. The A2AR agonist ATL-1223 (Lewis and Clark Pharmaceuticals, Charlottesville, Va) was administered as an infusion $(3.0 \mathrm{ng} / \mathrm{kg} / \mathrm{min})$ throughout all 4 hours of EVLP. The same weight-based volume of DMSO was administered as an infusion throughout EVLP. At the conclusion of EVLP, donor lungs were flushed antegrade with $500 \mathrm{~mL}$ of $4{ }^{\circ} \mathrm{C}$ Perfadex. Lungs were separated on the back table, and the donor left lung was cooled with topical cold slush for 15 minutes before transplantation.

\section{Left Lung Transplantation}

Recipient animals were anesthetized, weighed, and prepped for a left thoracotomy. Animals were intubated and maintained under general anesthesia with isoflurane. A central venous line with a PA catheter, arterial line, and oxygenation saturation probe was placed. Initial recipient $\mathrm{ABG}$ analysis was performed on $100 \%$ oxygen, and baseline vitals were recorded, including heart rate, blood pressure, PA pressure, and oxygenation saturation. A left thoracotomy was performed, and $50 \mathrm{mg}$ lidocaine was administered before dissection of the left hilum. Before clamping the left PA and ligating the left superior and inferior pulmonary veins, 5000 units of heparin were given and allowed to circulate for 5 minutes. The left mainstem bronchus was clamped, the pneumonectomy was completed, and the donor lung was placed in the chest. The bronchial anastomosis was completed with a running 4-0 Prolene suture, and the PA anastomosis was then completed with a running 5-0 Prolene suture. The recipient LA appendage was clamped, opened, and sewn to the donor LA cuff with a running 5-0 Prolene suture. Clamps were removed to establish reperfusion and ventilation. $\mathrm{ABG}$ analysis was performed, and vitals were recorded every 15 to 20 minutes during all 4 hours of reperfusion. Animals were ventilated with $100 \%$ oxygen throughout reperfusion. Intermittent gentle PEEP was applied to reduce atelectasis. Acid-base status was optimized by adjusting the respiratory rate at a constant tidal volume of $10 \mathrm{~mL} / \mathrm{kg}$. Intravenous fluids were given judiciously, and epinephrine was administered as needed. The A2AR agonist ATL-1223 was administered at $3.0 \mathrm{ng} / \mathrm{kg} / \mathrm{min}$ or an equivalent weight-based volume of DMSO was given as an infusion throughout reperfusion. ABG samples were obtained from the left superior and inferior pulmonary veins to determine the isolated oxygenation capacity of the transplanted left lung at the conclusion of reperfusion. Mean values were reported as final arterial oxygen partial pressure/fraction of inspired oxygen $\left(\mathrm{PaO}_{2} / \mathrm{FIO}_{2}\right)$ ratios. A final systemic ABG analysis was performed, the recipient was euthanized with Euthasol (Virbac AH, Inc, Fort Worth, Tex), and the left lung was explanted.

\section{Cytokine Expression}

Lung tissue samples were obtained from the left lower lobe (LLL), frozen at $-80^{\circ} \mathrm{C}$, and homogenized using a gentleMACS tissue dissociator (Miltenyi Biotec, Auburn, Calif) in a solution containing phosphate-buffered saline, $0.5 \%$ bovine serum albumin, and $2 \mathrm{mmol} / \mathrm{L}$ ethylenediaminetetraacetic acid. Total protein concentration was determined using a bicinchoninic acid protein assay (Pierce, Rockford, Ill). Enzyme-linked immunosorbent assays were performed to determine expression of interferon- $\gamma$ (RayBiotech, Inc, Norcross, Ga) and interleukin (IL)-1 $\beta$, IL-6, and IL-8 (Abcam, Cambridge, Mass). One sample in the ATL-E/R group had insufficient volume for the latter analyses. Cytokine concentrations were reported per $50 \mu \mathrm{g}$ total protein in each sample.

\section{Pulmonary Edema}

A bronchoalveolar lavage (BAL) of the left upper lobe (LUL) was performed with $50 \mathrm{~mL}$ normal saline. Total protein concentration was determined in BAL samples using a bicinchoninic acid protein assay as a measure of pulmonary edema. Lung tissue samples from the LUL $(\mathrm{n}=2$ /animal $)$ and LLL $(\mathrm{n}=3 /$ animal $)$ were weighed immediately and again after a stable weight was achieved through desiccation in a vacuum oven. Wet-to-dry weight ratios were determined as an additional measure of pulmonary edema. The wet-to-dry weight ratio for each lung was calculated as the mean of the ratios from all 5 lung tissue samples.

\section{Histology}

Lungs were inflation-fixed by filling the airways with formalin, and the lung was submerged in formalin overnight. Lung tissue samples from the $\operatorname{LUL}(\mathrm{n}=2 / \mathrm{animal})$ and LLL $(\mathrm{n}=3 / \mathrm{animal})$ were placed in $70 \%$ ethanol, embedded in paraffin, and stained with hematoxylin-eosin. The lung injury severity score was determined by a pathologist blinded to treatment group. The score ranged from 0 to 9 and was a composite sum of 3 individual components, including the number of neutrophils per high-powered field (score of $0,<5 ; 1,6-10 ; 2,11-20$; and score of 3,>20), interstitial infiltration (score of 0 , none; 1 , minimal; 2 , moderate; and 3 , severe), and alveolar edema (score of $0,<5 \% ; 1,6 \%-25 \% ; 2,26 \%-50 \%$; and 3 , $>50 \%$ ). The lung injury severity score for each lung was calculated as the mean of the scores from all 5 lung tissue samples.

\section{Statistical Analysis}

Experimental methods were designed to test the null hypothesis that no significant differences in lung IRI would be observed despite treatment with ATL-1223. Differences among groups were calculated using 1-way analysis of variance, and pairwise comparisons were made using Tukey's multiple comparisons test (GraphPad Prism version 6.0e, GraphPad Software Inc, La Jolla, Calif). An unpaired t test was used to calculate the differences between time points. Data are expressed as the mean \pm standard error of the mean.

\section{RESULTS \\ Donor Lung Oxygenation During Reperfusion}

There was no difference in mean initial $\mathrm{PaO}_{2} / \mathrm{FIO}_{2}$ ratios of donor animals among groups (Figure 1). However, after 4 hours of reperfusion, final $\mathrm{PaO}_{2} / \mathrm{FIO}_{2}$ ratios of donor lungs in both groups treated with ATL-1223 (ATL-E: $413.6 \pm 18.8 \mathrm{~mm} \mathrm{Hg}$; ATL-E/R: $430.1 \pm 26.4 \mathrm{~mm} \mathrm{Hg}$ ) were significantly higher than final $\mathrm{PaO}_{2} / \mathrm{FiO} 2$ ratios of 

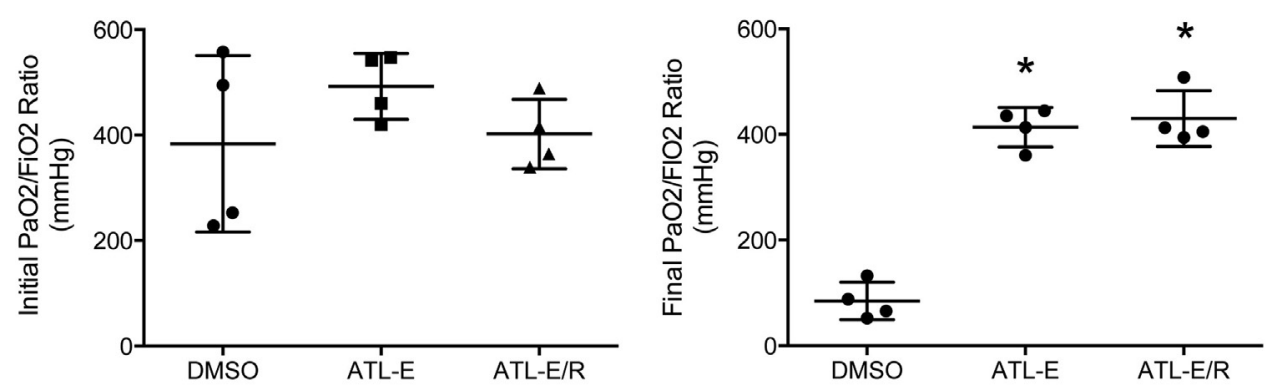

FIGURE 1. Comparison of initial and final $\mathrm{PaO}_{2} / \mathrm{FIO}_{2}$ ratios among groups. Initial donor $\mathrm{PaO}_{2} / \mathrm{FIO}_{2}$ ratios were obtained before procurement. Final PaO $/ \mathrm{FIO}_{2}$ ratios of donor lungs were determined from samples obtained from the left superior and inferior pulmonary veins after 4 hours of reperfusion. $* P<.0001$ versus DMSO. $\mathrm{PaO}_{2} / \mathrm{FIO}_{2}$, Arterial oxygen partial pressure/fraction of inspired oxygen; DMSO, dimethyl sulfoxide; ATL-E, A2AR agonist administration during EVLP; $A T L-E / R, \mathrm{~A} 2 \mathrm{AR}$ agonist administration during EVLP and reperfusion.

control donor lungs (DMSO: $84.8 \pm 17.7 \mathrm{~mm} \mathrm{Hg}$ ) $(P<.0001)$. Further administration of ATL-1223 during reperfusion did not significantly increase final $\mathrm{PaO}_{2} / \mathrm{FIO}_{2}$ ratios in the ATL-E/R group compared with the ATL-E group $(P=.85)$ (Figure 1).

Mean $\mathrm{PaO}_{2} / \mathrm{FIO}_{2}$ ratios of control donor lungs significantly worsened from baseline measurement in the donor animal to final assessment in the recipient. However, there was no significant difference between initial and final mean $\mathrm{PaO}_{2} / \mathrm{FIO}_{2}$ ratios of donor lungs in both groups treated with ATL-1223.

\section{Donor Lung Oxygenation During Ex Vivo Lung Perfusion}

Overall, mean $\mathrm{Po}_{2}$ gradients decreased from the first hour to the fourth hour of EVLP in all groups (Figure 2). Trends in $\mathrm{PO}_{2}$ gradients of individual lungs were highly variable throughout EVLP and were frequently below the $350 \mathrm{~mm}$ $\mathrm{Hg}$ threshold considered acceptable for clinical lung transplantation. ${ }^{10}$ Mean final values decreased significantly in the DMSO group from $334.2 \pm 16.7 \mathrm{~mm} \mathrm{Hg}$ after EVLP to $84.8 \pm 17.7 \mathrm{~mm} \mathrm{Hg}$ after reperfusion $(P<.0001)$ and decreased only slightly in the ATL-E group from $431.7 \pm 29.8 \mathrm{~mm} \mathrm{Hg}$ after EVLP to $413.6 \pm 18.8 \mathrm{~mm} \mathrm{Hg}$ after reperfusion. However, mean final values increased in the ATL-E/R group from $260.0 \pm 75.3 \mathrm{~mm} \mathrm{Hg}$ after EVLP to $430.1 \pm 26.4 \mathrm{~mm} \mathrm{Hg}$ after reperfusion $(P=.08)$.

\section{Physiologic Parameters During Ex Vivo Lung Perfusion}

Overall, mean values of peak airway pressure, dynamic compliance, and pulmonary vascular resistance (PVR) worsened throughout EVLP in all groups (Figure 3). Although certain individual parameters remained relatively stable or at times improved during EVLP, at least 1 of these 3 parameters in all donor lungs in all groups worsened by more than $15 \%$ between the first hour and fourth hour of EVLP (Figure 4), the threshold at which lungs would be deemed unsuitable for clinical lung transplantation. ${ }^{10}$

There were no differences among groups in mean percent change in peak airway pressure, dynamic compliance, or PVR throughout EVLP (Figure 4). Mean percent change in peak airway pressure and dynamic compliance were lowest in the DMSO group and highest in the ATL-E/R group. Mean percent change in PVR was highest in the ATL-E group.

\section{Cytokine Expression}

After 4 hours of reperfusion, there was a trend toward decreased expression of proinflammatory cytokines
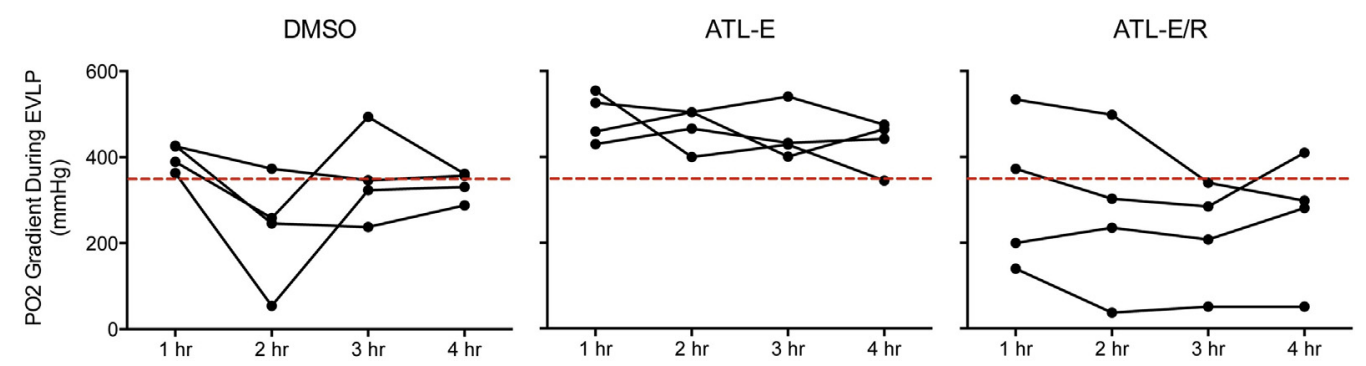

FIGURE 2. Trends in $\mathrm{PO}_{2}$ gradients throughout 4 hours of EVLP in DMSO, ATL-E, and ATL-E/R groups. The red line represents the $350 \mathrm{~mm} \mathrm{Hg}$ threshold for clinical lung transplantation. $\mathrm{PO}_{2}$, Oxygen tension; $E V L P$, ex vivo lung perfusion; $D M S O$, dimethyl sulfoxide; ATL-E, A2AR agonist administration during EVLP; $A T L-E / R, \mathrm{~A} 2 \mathrm{AR}$ agonist administration during EVLP and reperfusion. 
DMSO
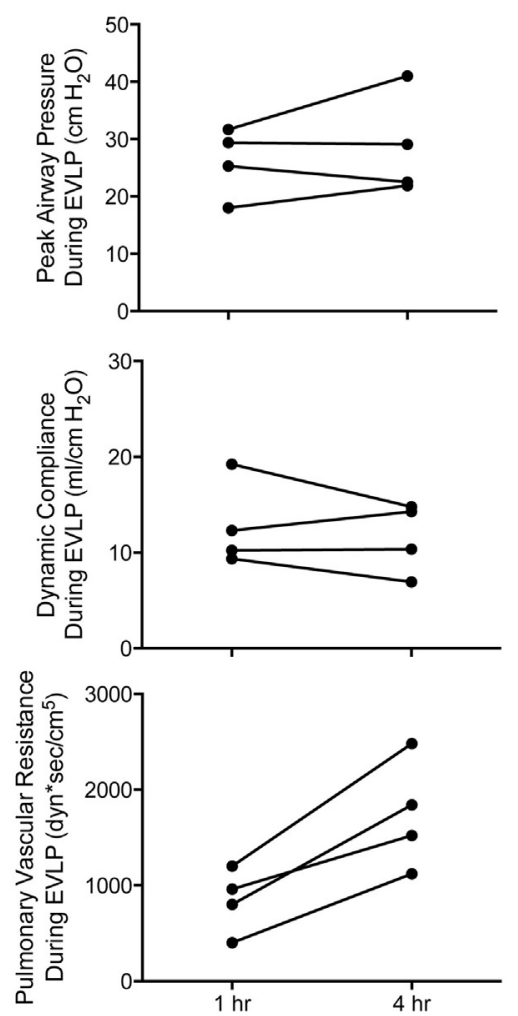

ATL-E
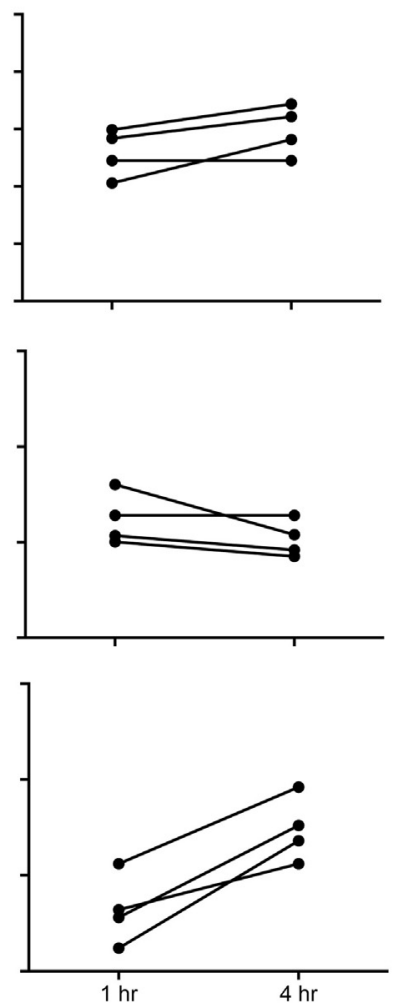

ATL-E/R
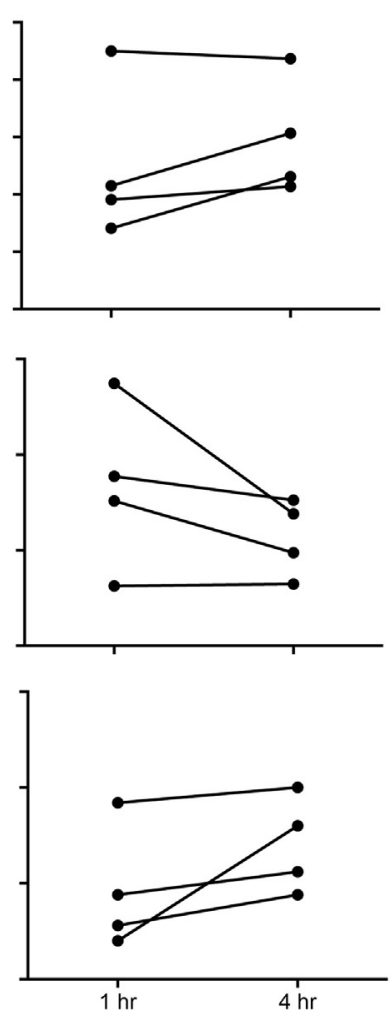

FIGURE 3. Changes in physiologic parameters throughout 4 hours of EVLP. Peak airway pressure, dynamic compliance, and PVR in the DMSO, ATL-E, and ATL-E/R groups. EVLP, Ex vivo lung perfusion; $D M S O$, dimethyl sulfoxide; ATL-E, A2AR agonist administration during EVLP; $A T L-E / R$, A2AR agonist administration during EVLP and reperfusion.

(interferon- $\gamma$, IL-1 $\beta$, IL-6, and IL-8) in the ATL-E and ATL-E/R groups compared with the DMSO group (Figure 5).

\section{Pulmonary Edema}

There was no significant difference in pulmonary edema among groups as measured by total protein concentration in BAL fluid or mean wet-to-dry weight ratios (Figure 6).

\section{Histology}

There was substantial variation in histologic appearance of lung injury within individual lung tissue sections. There was no difference in mean lung injury severity scores among groups (Figure 7) or in values of individual components of the overall score (neutrophil count, interstitial infiltration, and alveolar edema; not shown).

\section{DISCUSSION}

This study demonstrates that $\mathrm{PaO}_{2} / \mathrm{FIO}_{2}$ ratios after transplantation of DCD donor lungs subjected to prolonged 12-hour cold preservation are significantly improved after treatment with an A2AR agonist during EVLP. Outcomes highlight the potential of EVLP with targeted A2AR agonist delivery to augment the available donor lung pool by increasing the use of marginal donor lungs, including DCD donor lungs, and by extending the traditionally
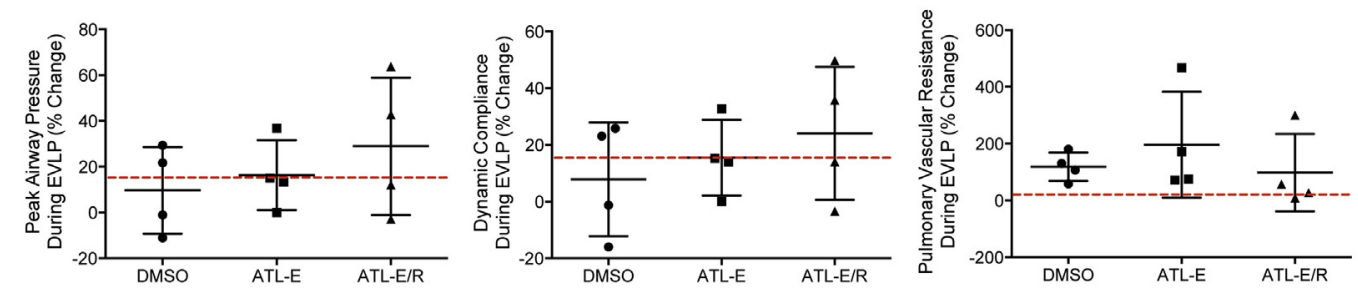

FIGURE 4. Percent change in peak airway pressure, dynamic compliance, and PVR between the first hour and the fourth hour of EVLP among groups. The red line represents the $15 \%$ threshold for clinical lung transplantation. EVLP, Ex vivo lung perfusion; DMSO, dimethyl sulfoxide; $A T L-E$, A2AR agonist administration during EVLP; ATL-E/R, A2AR agonist administration during EVLP and reperfusion. 

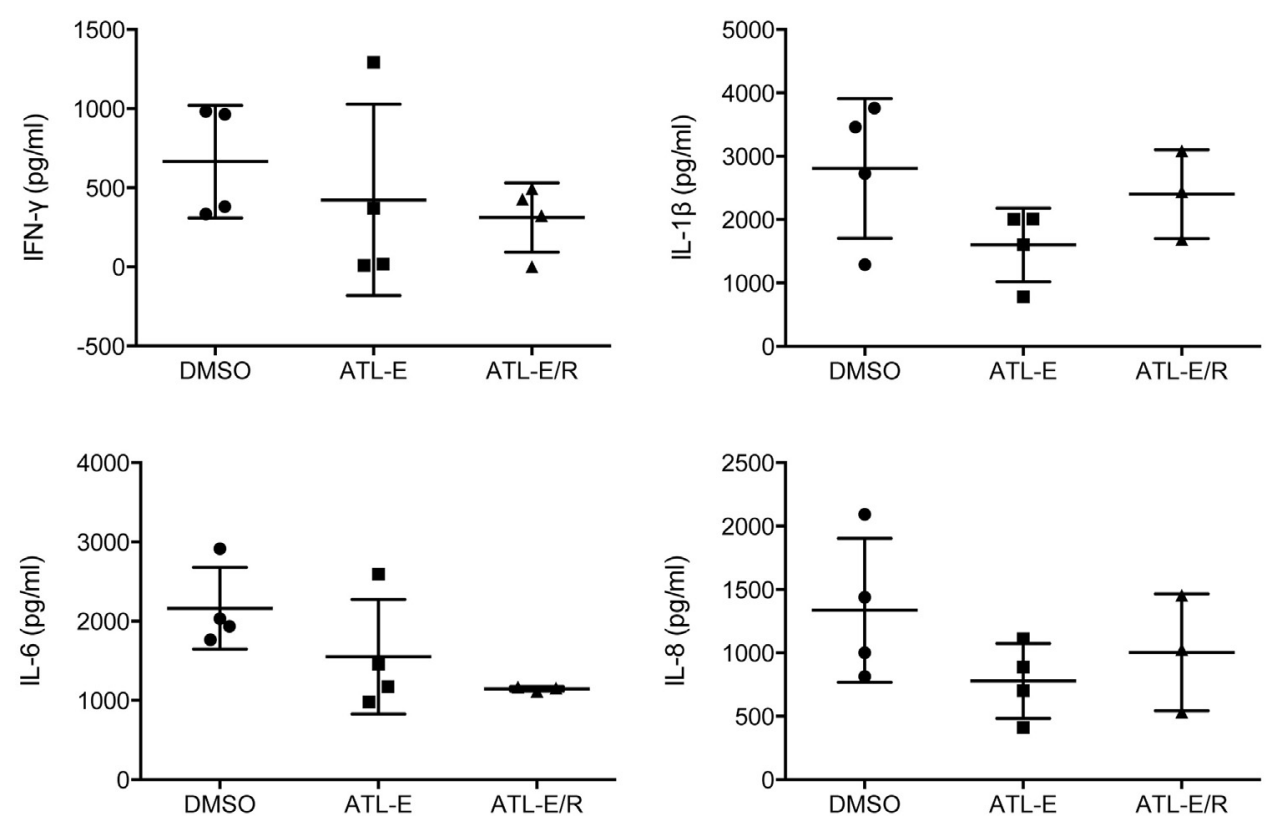

FIGURE 5. Proinflammatory cytokine levels in lung tissue after 4 hours of reperfusion. $I L$, Interleukin; $I F N-\gamma$, interferon gamma; $D M S O$, dimethyl sulfoxide; ATL-E, A2AR agonist administration during EVLP; $A T L-E / R$, A2AR agonist administration during EVLP and reperfusion.

recognized 6-hour time constraint for cold preservation, thereby decreasing geographic restrictions of donor lung procurement.

IRI manifests as PGD within the first 72 hours after lung transplantation. PGD severity is determined by oxygenation capacity and the radiographic appearance of pulmonary edema within the transplanted lung(s), with grade 0 PGD occurring in the presence of $\mathrm{PaO}_{2} / \mathrm{FIO}_{2}$ ratios greater than $300 \mathrm{~mm} \mathrm{Hg}$ and normal lung fields and grades 1 to 3 PGD occurring in the presence of diffuse pulmonary infiltrates and $\mathrm{PaO}_{2} / \mathrm{FIO}_{2}$ ratios greater than $300 \mathrm{~mm} \mathrm{Hg}$, between 200 and $300 \mathrm{~mm} \mathrm{Hg}$, and less than $200 \mathrm{~mm} \mathrm{Hg}$, respectively. ${ }^{12,13}$ PGD severity correlates with outcomes after lung transplantation. Patients who develop grade 3 PGD have significantly increased operative mortality ${ }^{14}$ and higher rates of late mortality and impaired pulmonary function compared with patients with grade 0 or 1 PGD. ${ }^{15}$ In this study, final $\mathrm{PaO}_{2} / \mathrm{FIO}_{2}$ ratios of the transplanted left lungs from all animals in the ATL-E and ATL-E/R groups were greater than $300 \mathrm{~mm} \mathrm{Hg}$, whereas final $\mathrm{PaO}_{2} / \mathrm{FiO}_{2}$ ratios of the transplanted left lungs from all animals in the DMSO group were less than $200 \mathrm{~mm} \mathrm{Hg}$. Although radiographic imaging was not performed in this study, there was no difference in pulmonary edema among groups. Thus, administration of ATL-1223 to donor lungs during EVLP appears to have reduced IRI from grade 3 PGD to grade 1 PGD. These results are similar to prior porcine models of lung transplantation demonstrating a reduction in IRI after A2AR agonist treatment during $\mathrm{EVLP}^{11,16}$ or during reperfusion. ${ }^{17,18}$

Further administration of ATL-1223 during reperfusion did not significantly decrease IRI beyond that achieved by administration of ATL-1223 during EVLP alone, because $\mathrm{PaO}_{2} / \mathrm{FIO}_{2}$ ratios from the ATL-E/R and ATL-E groups were not different. This finding suggests that the inflammatory cascade mediating IRI is initiated by resident immune
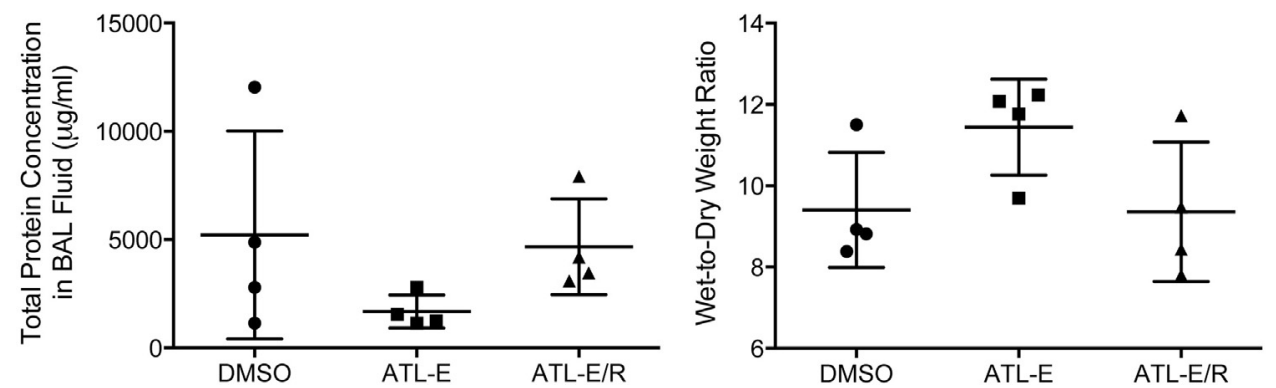

FIGURE 6. Pulmonary edema after 4 hours of reperfusion as measured by total protein concentration in BAL fluid and lung wet-to-dry weight ratios. $B A L$, Bronchoalveolar lavage; $D M S O$, dimethyl sulfoxide; ATL-E, A2AR agonist administration during EVLP; ATL-E/R, A2AR agonist administration during EVLP and reperfusion. 

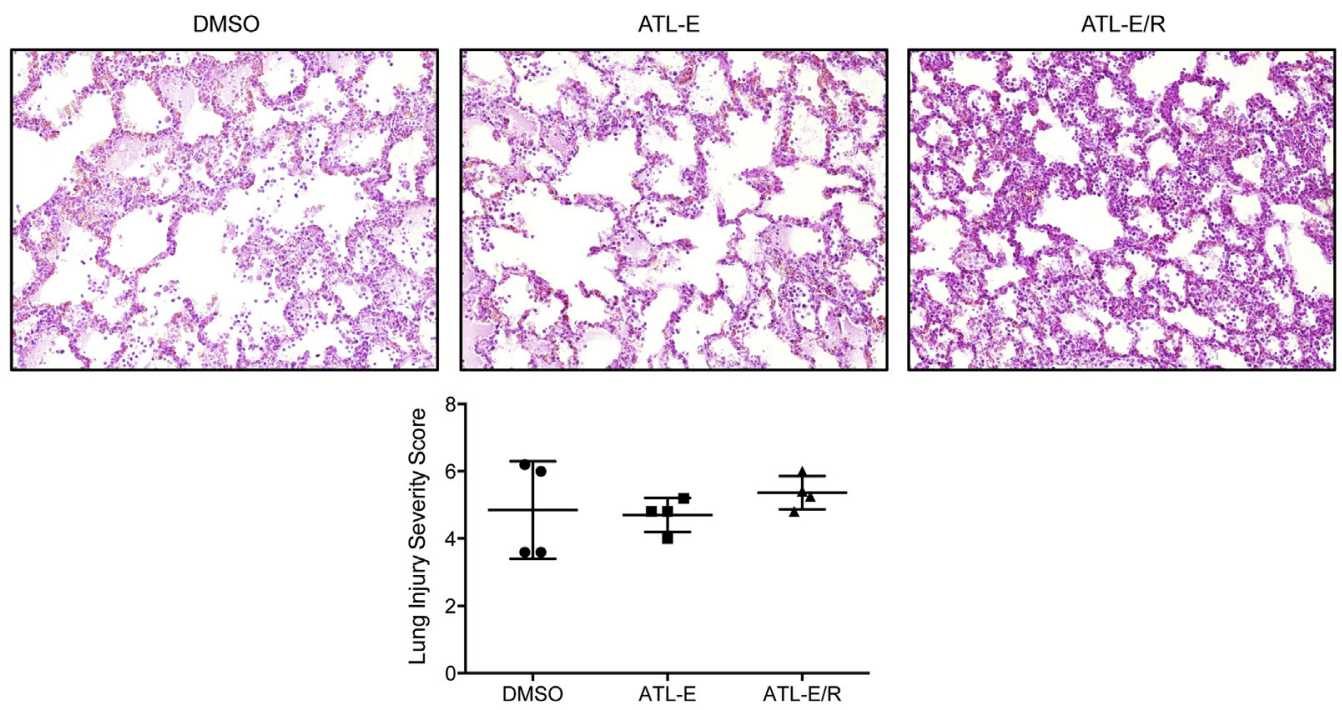

FIGURE 7. Top, Representative lung histology (hematoxylin and eosin stain at $20 \times$ magnification) after 4 hours of reperfusion in DMSO, ATL-E, and ATL-E/R groups. Bottom, Comparison of mean lung injury severity scores among groups as determined from histology. DMSO, Dimethyl sulfoxide; $A T L-E$, A2AR agonist administration during EVLP; ATL-E/R, A2AR agonist administration during EVLP and reperfusion.

cells within the donor lung that are inactivated by ATL1223 during EVLP, and that this inhibition persists during reperfusion. Previous studies have shown distinct populations of cells to be important at different stages of lung IRI: resident macrophages and invariant natural killer $\mathrm{T}$ cells in the donor lung in an early phase and circulating neutrophils in the recipient in a later phase. ${ }^{19-21}$ In prior animal models of lung IRI, administration of an A2AR agonist to the donor animal before lung procurement decreased IRI to a similar extent as administration of the A2AR agonist during reperfusion, suggesting that both donor and recipient populations of immune cells are important in the development of lung IRI. ${ }^{18,22}$ In a rabbit model of lung IRI, pretreatment of the donor with the A2AR agonist resulted in a significant decrease in the number of pulmonary macrophages during reperfusion compared with treatment of the recipient at a later time. ${ }^{22}$ Taken together, these studies support a role for early activation of resident immune cells in the donor lung in the initiation of IRI. EVLP provides an ideal platform for isolated drug delivery to inactivate these cells in marginal donor lungs, thereby avoiding side effects associated with systemic therapy in the donor or recipient.

\section{Study Limitations}

The accuracy of ex vivo evaluation in predicting lung function after transplantation has been shown to depend on physiologic parameters (peak airway pressure, dynamic compliance, and $\mathrm{PVR}$ ) more than on $\mathrm{PO}_{2}$ gradients during EVLP $^{23}$ In a previous clinical trial, marginal donor lungs rehabilitated with EVLP were transplanted if physiologic parameters did not deteriorate by more than $15 \%$ and if
$\mathrm{PO}_{2}$ gradients were greater than $350 \mathrm{~mm} \mathrm{Hg}$ during 4 hours of EVLP. ${ }^{10}$ No single lung in the present study met these inclusion criteria after 4 hours of EVLP. Physiologic parameters and oxygenation capacity during EVLP were frequently superior in the DMSO group, yet these lungs were associated with severe IRI in the recipient. Conversely, lungs treated with ATL-1223 often had inferior pulmonary function during EVLP, yet had mean $\mathrm{PaO}_{2} / \mathrm{FIO}_{2}$ ratios greater than $400 \mathrm{~mm} \mathrm{Hg}$ after 4 hours of reperfusion. Therefore, neither physiologic parameters nor $\mathrm{Po}_{2}$ gradients during EVLP were predictive of lung function during reperfusion in this preclinical porcine model. Future studies will require identification of more reliable markers of lung function during EVLP that correlate with pulmonary function in the recipient before lungs can be safely transplanted clinically.

A related limitation of this study is the lack of data to explain how ATL-1223 administration promoted superior final $\mathrm{PaO}_{2} / \mathrm{FIO}_{2}$ ratios in the treated groups. There was a trend toward decreased proinflammatory cytokine expression in these groups, and statistical significance may have been achieved with more animals per group. It is unclear why there was no difference in pulmonary edema or histologic appearance of lung injury among groups. There was considerable variation within individual lung tissue sections, which made calculation of a single representative lung injury severity score somewhat challenging, and this score may not accurately reflect differences in IRI among groups. Instead, the most established and clinically applicable measure of IRI is the $\mathrm{PaO}_{2} / \mathrm{FiO}_{2}$ ratio after transplantation, which was significantly increased in recipients of lungs treated with ATL-1223 during EVLP. 
Clinically, potential lung donors are evaluated with imaging modalities, including computed tomography and bronchoscopy, before a decision is made regarding donor lung eligibility. Imaging of porcine donor lungs was not performed before procurement in this study. Therefore, it was not possible to screen donor lungs for intrinsic pulmonary disease. There were several instances in which it became increasingly difficult to ventilate donor lungs during reperfusion in all groups because of severe baseline pulmonary disease, and these animals were not included in the final analysis. This demonstrates that pulmonary injury within a subset of donor lungs is beyond rehabilitation with targeted ATL-1223 treatment during EVLP. Moreover, severe IRI occurred in all control donor lungs without apparent pulmonary disease. These findings show that EVLP alone without concomitant ATL-1223 treatment is unable to prevent IRI after transplantation of DCD donor lungs subjected to prolonged 12-hour cold preservation. Quantifying a threshold of irreversible donor lung injury will be an important component of clinical translation of animal models of EVLP.

\section{CONCLUSIONS}

EVLP with targeted A2AR agonist treatment attenuates IRI after transplantation of DCD donor lungs subjected to prolonged 12-hour cold preservation in a preclinical porcine model. Pulmonary function during EVLP was not predictive of oxygenation capacity during reperfusion, as donor lungs that would have been rejected clinically after EVLP had postoperative $\mathrm{PaO}_{2} / \mathrm{FIO}_{2}$ ratios greater than $400 \mathrm{~mm}$ $\mathrm{Hg}$ if treated with an A2AR agonist during EVLP. Translation of this study may significantly expand the donor lung pool.

\section{Conflict of Interest Statement}

Authors have nothing to disclose with regard to commercial support.

You can watch a Webcast of this AATS meeting presentation by going to: http://webcast.aats.org/2015/Video/ Monday/04-27-15_6B_1736_Wagner.mp4.

The authors thank Dr Curtis Tribble and Dr Benjamin Kozower for mentorship and Sheila Hammond, Tony Herring, and Cindy Dodson for technical assistance.

\section{References}

1. Cypel M, Keshavjee S. Strategies for safe donor expansion: donor management, donations after cardiac death, ex vivo lung perfusion. Curr Opin Organ Transplant. 2013;18:513-7.

2. Pierre AF, Sekine Y, Hutcheon MA, Waddell TK, Keshavjee SH. Marginal donor lungs: a reassessment. J Thorac Cardiovasc Surg. 2002;123:421-8.

3. Botha P, Trivedi D, Weir CJ, Searl CP, Corris PA, Dark JH, et al. Extended donor criteria in lung transplantation: impact on organ allocation. J Thorac Cardiovasc Surg. 2006;131:1154-60.
4. King RC, Binns OA, Rodriguez F, Kanithanon RC, Daniel TM, Spotnitz WD, et al. Reperfusion injury significantly impacts clinical outcome after pulmonary transplantation. Ann Thorac Surg. 2000;69:1681-5.

5. Christie JD, Sager JS, Kimmel SE, Ahya VN, Gaughan C, Blumenthal NP, et al Impact of primary graft failure on outcomes following lung transplantation. Chest. 2005;127:161-5.

6. Fiser SM, Tribble CG, Long SM, Kaza AK, Kern JA, Jones DR, et al. Ischemia-reperfusion injury after lung transplantation increases risk of late bronchiolitis obliterans syndrome. Ann Thorac Surg. 2002;73:1041-8.

7. Kreisel D, Krupnick AS, Puri V, Guthrie TJ, Trulock EP, Meyers BF, et al. Shortand long-term outcomes of 1000 adult lung transplant recipients at a single center. J Thorac Cardiovasc Surg. 2011;141:215-22.

8. Steen S, Sjoberg T, Pierre L, Liao Q, Eriksson L, Algotsson L. Transplantation of lungs from a non-heart-beating donor. Lancet. 2001;357:825-9.

9. Cypel M, Yeung JC, Hirayama S, Rubacha M, Fischer S, Anraku M, et al. Technique for prolonged normothermic ex vivo lung perfusion. J Heart Lung Transplant. 2008;27:1319-25.

10. Cypel M, Yeung JC, Liu M, Anraku M, Chen F, Karolak W, et al. Normothermic ex vivo lung perfusion in clinical lung transplantation. $N$ Engl J Med. 2011;364 $1431-40$.

11. Mulloy DP, Stone MS, Crosby IK, LaPar DJ, Sharma AK, Webb DV, et al Ex vivo rehabilitation of non-heart-beating donor lungs in preclinical porcine model: delayed perfusion results in superior lung function. J Thorac Cardiovasc Surg. 2012;144:1208-16.

12. Christie JD, Raemdonck DV, de Perrot M, Barr M, Keshavjee S, Arcasoy S, et al Working Group on Primary Lung Graft Dysfunction, Report of the ISHLT Working Group on primary lung graft dysfunction Part I: Introduction and Methods. J Heart Lung Transplant. 2005;24:1451-3.

13. Christie JD, Carby M, Bag R, Corris P, Hertz M, Weill D. Report of the ISHLT Working Group on primary lung graft dysfunction Part II: Definition. A consensus statement of the International Society for Heart and Lung Transplantation. J Heart Lung Transplant. 2005;24:1454-9.

14. Christie JD, Ahya VN, Sager JS, Pocchetino A, DeMissie E, Zhou L, et al ISHLT PGD grade predicts differential mortality following lung transplantation. J Heart Lung Transplant. 2005;24(suppl):S71-2.

15. Whitson BA, Prekker ME, Herrington CS, Whelan TP, Radosevich DM Hertz MI, et al. Primary graft dysfunction and long-term pulmonary function after lung transplantation. J Heart Lung Transplant. 2007;26:1004-11.

16. Emaminia A, LaPar DJ, Zhao Y, Steidle JF, Harris DA, Laubach VE, et al Adenosine A2A agonist improves lung function during ex vivo lung perfusion. Ann Thorac Surg. 2011;92:1840-6.

17. Reece TB, Ellman PI, Maxey TS, Crosby IK, Warren PS, Chong TW, et al Adenosine A2A receptor activation reduces inflammation and preserves pulmonary function in an in vivo model of lung transplantation. J Thorac Cardiovasc Surg. 2005;129:1137-43.

18. LaPar DJ, Laubach VE, Emaminia A, Crosby IK, Hajzus VA, Sharma AK, et al Pretreatment strategy with adenosine A2A receptor agonist attenuates reperfusion injury in a preclinical porcine lung transplantation model. J Thorac Cardiovasc Surg. 2011;142:887-94.

19. Fiser SM, Tribble CG, Long SM, Kaza AK, Cope JT, Laubach VE, et al. Lung transplant reperfusion injury involves pulmonary macrophages and circulating leukocytes in a biphasic response. J Thorac Cardiovasc Surg. 2001;121: 1069-75.

20. Zhao M, Fernandez LG, Doctor A, Sharma AK, Zarbock A, Tribble CG, et al. Alveolar macrophage activation is a key initiation signal for acute lung ischemiareperfusion injury. Am J Physiol Lung Cell Mol Physiol. 2006;291:L1018-26.

21. Sharma AK, LaPar DJ, Zhao Y, Li L, Lau CL, Kron IL, et al. Natural killer T cellderived IL-17 mediates lung ischemia-reperfusion injury. Am J Respir Crit Care Med. 2011;183:1539-49.

22. Gazoni LM, Laubach VE, Mulloy DP, Bellizzi A, Unger EB, Linden J, et al Additive protection against lung ischemia-reperfusion injury by adenosine A2A receptor activation before procurement and during reperfusion. $J$ Thorac Cardiovasc Surg. 2008;135:156-65.

23. Yeung JC, Cypel M, Machuca TN, Koike T, Cook DJ, Bonato R, et al Physiologic assessment of the ex vivo donor lung for transplantation. J Heart Lung Transplant. 2012;31:1120-6.

Key Words: lung transplantation, ex vivo lung perfusion, adenosine A2A receptor agonist, donation after cardiac death, prolonged cold preservation 


\section{Discussion}

Dr A. Krupnick (St Louis, Mo). This was great work, and obviously you guys are on the cutting edge of this therapy to recondition lungs and ameliorate IRI. In several of your groups all animals were treated with your antagonist during reperfusion, but you never included a group where it was given to just the animal after reperfusion, any reason for that?

Dr Wagner. Why we did not include a group with treatment only during reperfusion?

Dr Krupnick. Correct.

Dr Wagner. One of the goals in this study was to try to focus treatment during EVLP to avoid side effects in the donor or recipient.

Dr Krupnick. Okay. Got you. That makes sense. You speculated that this is affecting organ resident immune cells. According to the pattern of receptors, can you speculate which cell is important (macrophage, neutrophil) and why not endothelial cells? Could it stabilize endothelial cells and decrease some of the integrins that would lead to IRI?

Dr Wagner. A2A receptors are present on macrophages and invariant natural killer $\mathrm{T}$ cells in the donor lung and on circulating neutrophils in the recipient. One of the projects going forward will be to determine how ATL-1223 treatment during EVLP is changing those cells. We're currently working with confocal microscopy to determine if we are changing the macrophage phenotype to an M2 anti-inflammatory phenotype.

Dr Krupnick. That's great work.

Dr M. Cypel (Toronto, Ontario, Canada). I was a bit surprised with the degree of injury you had in the control group, you know, 15 minutes of warm ischemia and 12 hours of cold ischemia, it's pretty minor injury, and yet you had a P/F ratio of $83 \%$. So I would just like your comment on that. But also, when you showed all your lung function decline during EVLP, was that due to pulmonary edema? Did you have any measure of that? And if the lungs were severely edematous at the end of EVLP, why did they work so well after transplantation?

Dr Wagner. We did look at pulmonary edema. We looked at protein concentration in BAL fluid and at wet-to-dry weight ratios.
There was no difference in pulmonary edema with either method. I think part of the reason for that is that perfusate is replaced during EVLP clinically. However, we were not able to do that. So the lungs in all groups became quite edematous at the end of EVLP.

I think you raise an interesting point, because in our DMSO control group, we're showing that EVLP after 15 minutes of warm ischemia and 12 hours of cold preservation is unable to prevent significant IR injury, so we're going to need to quantify a threshold of donor lung injury in translating animal models of EVLP.

Dr Cypel. Did you have any measure of lung injury other than pulmonary vein blood gas?

Dr Wagner. We looked at $\mathrm{PO}_{2}$ ratios in the recipient at the end of reperfusion. We looked at proinflammatory cytokine expression. We also looked at histologic injury. However, that was difficult to quantify because there was a lot of variation within individual lung tissue sections.

Dr S. Keshavjee (Toronto, Ontario, Canada). You started out by saying that EVLP has the potential to improve lung use and you've developed a therapy to be implemented during EVLP, but you then showed that using your therapy, with EVLP in your hands, all the lungs deteriorated, and therefore you couldn't really say that the lungs were getting better. However, you then concluded by saying this potential has the possibility to improve lung use. How do you reconcile those 2 statements? All the lungs deteriorated, and you went ahead and transplanted them. You're not likely going to do that in a human.

Dr Wagner. Right. That's a great point. As I said previously, not being able to replace the EVLP perfusate played a role in all of the lungs becoming edematous. I think one of the main future avenues in EVLP is going to be to identify biomarkers, as your group is doing, to identify those lungs that will have superior function after transplant.

Dr Keshavjee. I would also advise that you troubleshoot your system, because 15 minutes of warm ischemia plus 12 hours of cold is actually a pretty minimal injury to see that degree of deterioration, so one suspects that something else must be going on.

Dr Wagner. Thank you. 